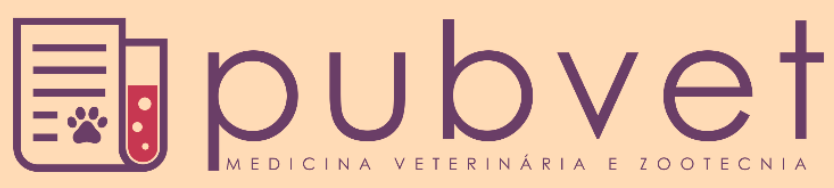

https://doi.org/10.31533/pubvet.v14n10a665.1-9

\title{
Salmonella spp. como agente causal em Doenças Transmitidas por Alimentos e sua importância na saúde pública: Revisão
}

\author{
Karina Paula Oliveira dos Santos ${ }^{1 *}$, Ana Claudia dos Santos Reis Faria ${ }^{1}$, Débora Patrícia \\ Andrade Silva ${ }^{1}$, Priscila Fortunato Lisboa ${ }^{1 \oplus}$, Alexandre de Pina $\operatorname{Costa}^{2}{ }^{\mathbb{9}}$, Fabiana Batalha \\ Knackfuss $^{2}$ (9)
}

${ }^{I}$ Graduanda em Medicina Veterinária pela Universidade do Grande Rio, Campus I. Duque de Caxias - RJ, Brasil.

${ }^{2}$ Professor (a) adjunto do curso de Medicina Veterinária da Universidade do Grande Rio, Campus I. Duque de Caxias - RJ, Brasil.

*Autor para correspondência, E-mail: karinasanntos9@gmail.com

Resumo. A Salmonelose é uma enfermidade de grande importância mundial em Doenças Transmitidas por Alimentos (DTAs). No Brasil, a Salmonella spp. é o segundo maior agente causador de doença envolvida nos surtos de DTAs, sendo a espécie entérica a que mais acomete os seres humanos através do consumo de água e alimentos contaminados. Após a ingestão do alimento contaminado pela bactéria, esta faz adesão, invasão, se replica e provoca danos no hospedeiro. O indivíduo acometido pode ser tratado com uso de antibióticos caso apresente febre entérica, porém nos casos de gastroenterite o uso não é indicado. Dessa forma, a prevenção da salmonelose é de grande relevância, pois nem todos os casos há sintomatologia ou notificação. O objetivo deste trabalho foi realizar uma revisão de literatura e abordar as informações sobre as formas de transmissão, sintomatologia apresentada pelos indivíduos acometidos, os alimentos envolvidos, a patogenicidade, medidas profiláticas e a importância na saúde pública, da Salmonella spp., visto que é de grande importância o conhecimento dos surtos para que assim, sejam adotadas medidas de monitoramento e controle da doença.

Palavras chave: alimentos, doença, Salmonella, saúde pública

\section{Salmonella spp. as the causal agent in Foodborne Diseases and its importance in public health: Review}

Abstract. Salmonellosis is a disease of great global importance worldwide in Foodborne Diseases (DTAs). In Brazil, Salmonella spp. it is the second major causative agent of disease involved in the outbreaks of DTAs, and the enteric species is the one that most affects humans through the consumption of contaminated water and food. After eating the food contaminated by the bacteria, it adheres, invades, replicates and causes damage to the host. The affected individual can be treated with antibiotics if he has an enteric fever, but in cases of gastroenteritis the use is not indicated. Thus, the prevention of salmonellos is of great relevance, since not all cases have symptoms or notification. The objective of this work was to carry out a literature review and address information on the forms of transmission, symptoms presented by the affected individuals, the foods involved, the pathogenicity, prophylactic measures and the importance in public health, of Salmonella spp., Since it is of knowledge of outbreaks is of great importance so that measures to monitor and control the disease are adopted.

Keywords: food, disease, Salmonella, public health 


\section{Salmonella spp. como agente causal de las enfermedades transmitidas por los alimentos y su importancia en la salud pública: Revisión}

Resumen. La salmonelosis es un padecimiento de gran importancia mundial en
enfermedades transmitidas por los alimentos (DTAs). En Brasil, Salmonella spp. Es el
segundo agente causante principal de enfermedades involucradas en los brotes de DTAs, y
la especie entérica que más afecta a los humanos a través del consumo de agua y alimentos
contaminados. Después de comer los alimentos contaminados por la bacteria, se adhiere,
invade, replica y causa daño al huésped. El individuo afectado puede ser tratado con
antibióticos si tiene fiebre entérica, pero en casos de gastroenteritis el uso no está indicado.
Por lo tanto, la prevención de la salmonelosis es de gran relevancia, ya que no todos los
casos tienen síntomas o notificación. El objetivo de este trabajo es revisar la literatura y
abordar la información sobre las formas de transmisión, los síntomas presentados por las
personas afectadas, los alimentos involucrados, la patogenicidad, las medidas profilácticas
y la importancia en la salud pública de Salmonella spp., Ya que el conocimiento de los
brotes es de gran importancia para que se adopten medidas para controlar esta enfermedad.

Palabras clave: comida, enfermedades, Salmonella, salud pública

\section{Introdução}

A bactéria Salmonella spp. tem uma grande importância em Doenças Transmitidas por Alimentos (DTAs), estando entre os principais patógenos envolvidos (Rodrigues, 2016). As bactérias pertencentes ao grupo de Salmonellas têm sua transmissão principalmente relacionada a animais e produtos de origem animal que são consumidos pelos seres humanos, sendo microrganismos que conseguem sobreviver congelados por longo período (Brooks et al., 2014).

Para Shinohara et al. (2008) a maioria dos sorotipos da Salmonella é patogênica ao homem, causando sintomas diferentes devido a variação dos mecanismos de patogenicidade, idade e sistema imune do hospedeiro. Entre as espécies da bactéria que acomete o homem, a entérica é a que está mais relacionada a alimentos, pois contamina facilmente ovos já que aves infectadas são assintomáticas (Lima \& Sousa, 2002).

Segundo Brooks et al. (2014) são reconhecidos cerca de 2.500 sorotipos de Salmonellas, incluindo mais de 1.400 no grupo de mesclagem do DNA I que podem contaminar o ser humano. No Brasil, entre os anos de 2009 a 2018 foram notificados 2.431 surtos de DTAs, estando a Salmonella spp. em segundo lugar com 11,3\% em relação aos agentes etiológicos envolvidos (Ministério da Saúde, 2019). Todavia, de acordo com Ranthum (2002) os sistemas de vigilância sanitária e epidemiológica não são eficientes, uma vez que ocorrem riscos devido à subnotificação que contribuí para a ineficácia do controle dessas doenças.

O objetivo deste trabalho foi realizar uma revisão de literatura e abordar informações sobre a Salmonella spp. em relação à sua sintomatologia, formas de transmissão, alimentos envolvidos, sua patogenicidade, prevenção e a importância na saúde pública, levando em consideração que esse agente é de grande relevância na saúde humana, principalmente em função dos riscos que a bactéria representa aos consumidores.

\section{Etiologia}

De acordo com Lima \& Sousa (2002) a bactéria faz parte da família Enterobacteriaceae, habitando o trato intestinal do homem e animais. Conforme Brooks et al. (2014) a classificação das Salmonellas é de grande dificuldade, já que os microrganismos representam mais uma continuidade do que uma espécie que seja definida. São bacilos Gram-negativos, não esporulados, anaeróbios facultativos, apresentam oxidase negativa e em sua maioria são flagelados. Seu $\mathrm{pH}$ pode variar de 4 a 9 , sendo o ideal para reprodução em torno de 7 , sua temperatura para crescimento varia de 5 a $45^{\circ} \mathrm{C}$, porém $37^{\circ} \mathrm{C}$ aparece como predileção (Mendonça, 2016) e segundo Franco \& Landgraf (2005) essa temperatura pode mudar de acordo com cada sorotipo. 
Atualmente o gênero Salmonella é dividido em duas espécies que são: Salmonella entérica e a Salmonella bongori, essas por sua vez possuem várias espécies e sorotipos. Se tratando da Salmonella entérica, ela é dividida em cinco subespécies, a subespécie I (entérica), subespécie II (salamae), subespécie IIIa (arizonae), subespécie IIIb (diarizonae), subespécie IV (houtenae) e a subespécie VI (indica). A Salmonella entérica subespécie entérica é considerada a de maior importância na saúde pública, uma vez que suas cepas são as principais responsáveis por causarem doenças em humanos (Brooks et al., 2014).

\section{Sinais Clínicos}

De acordo com Brooks et al. (2014) existem quatro sorotipos de Salmonellas que podem causar doença e devem ter rotina de identificação devido sua relevância clínica, que são eles: Salmonella paratyphi A (sorogrupo A), Salmonella paratyphi B (sorogrupo B), Salmonella choleraesuis (sorogrupo C1) e a Salmonella tiphy (sorogrupo D). Usualmente a dose infectante varia de $10^{5}$ a $10^{8}$ unidades formadoras de colônia (Ministério da Saúde, 2011), e segundo Neves (2016) em imunossuprimidos, idosos e crianças a dose infectante pode ser menor, sendo também o grupo mais vulnerável a apresentar os sintomas mais severos (Simôes et al., 2010).

A febre tifoide está relacionada com Salmonellas tiphy e paratyphi, já as de febre não tifoide estão envolvidas as Salmonellas typhimutium e enteritidis (Brooks et al., 2014). Os sintomas relacionados à febre tifoide são graves e pessoas acometidas apresentam febre alta, septicemia, diarreia e vômitos. Seu período de incubação normalmente varia de 7 a 21 dias, podendo chegar a oito semanas a duração da enfermidade (Connor \& Schwartz, 2005), consequentemente levando a morte (Ministério da Saúde, 2011).

Connor \& Schwartz (2005) definiram que se tratando da febre não tifoide, os sinais clínicos são mais leves quando comparados à febre tifoide, já que a mesma pode estar relacionada a ocorrência de septicemia e regularmente gerar um quadro de gastroenterites, febre e vômito. Seu período de incubação normalmente é de 6 a 48 horas, tendo uma média de três semanas a duração da doença.

Nas infecções ligadas às demais Salmonellas também ocorrem quadros de diarreia e vômito, incluindo, além disso, febre moderada, dor abdominal, mal estar geral, cansaço, perda de apetite e calafrios (Ministerio da Saúde, 2019). A manifestação dos sintomas ocorre de 12 a 36 horas após a ingestão do alimento (Galdino et al., 2013) e de acordo com Shinohara et al. (2008) pode perdurar por até 72 horas, óbitos são raros quando se trata desse tipo de infecção.

\section{Transmissão}

De acordo com Silva (2012) as contaminações em alimentos acontecem por meio de agentes químicos, físicos e biológicos. Os alimentos podem ser contaminados no plantio, através do uso exacerbado dos agrotóxicos. Além do solo e da água, a falta de higienização das mãos também é um fator relacionado à contaminação. $\mathrm{O}$ armazenamento e refrigeração incorreta do produto propiciam a contaminação até mesmo na hora de consumo.

Quando se trata da febre tifoide, a transmissão ocorre principalmente através da ingestão de água ou de alimentos que foram contaminados com fezes ou urina de pessoas já infectadas. Essa doença está ligada a falta de saneamento básico, analfabetismo e a pobreza em geral, pois são importantes facilitadores da contaminação, favorecendo assim a transmissão fecal-oral e mantendo a cadeia de transmissão (Fica et al., 2001).

Uma importante forma de transmissão da bactéria tem sido através da ingestão de alimentos crus, mal cozidos ou mal higienizados (Conceição et al., 2007). No estudo de Nadvorny et al. (2018) alimentos preparados com ovos estavam presentes em $72,2 \%$ nos surtos de Salmonelose que foram avaliados no estado do Rio Grande do Sul no ano de 2000. Além disso, para Malheiros et al. (2007) os alimentos que envolvam como ingrediente no seu preparo a utilização de ovos crus, representam um dos principais meios de transmissão da Salmonela spp. 


\section{Mecanismo de Patogenicidade}

Patogenicidade por definição é a competência que um microrganismo tem de provocar doença, diferentemente da virulência que significa a intensidade da doença propiciada pelo patógeno (Brooks et al., 2009).

Segundo o Ministério da Saúde (2011), salmonelose é uma doença que acomete humanos causada por uma bactéria do gênero Salmonella spp, adquirida através do consumo de água e alimentos contaminados. Ao ser ingerida, a bactéria Salmonella penetra e passa pela camada epitelial intestinal, atinge e penetra na camada onde as células epiteliais estão ancoradas (lâmina própria), e se multiplicam. As células de defesa do sistema imunológico como macrófagos e monócitos fagocitam essas bactérias, ocasionando uma resposta inflamatória. Neste caso, ocorre uma infecção na mucosa intestinal, porém a inflamação também pode estar ligada a liberação de prostaglandinas, estas são responsáveis por excitarem as enzimas adenilciclase, resultando em uma maior secreção de eletrólitos e água, ocasionando uma diarreia aquosa.

Para que ocorra uma gastroenterite, é necessário que ocorra uma quantidade significativa do número de salmonelas ingeridas e depende também do sorotipo, alcançando a dose infectante (Shinohara et al., 2008).

De acordo com Ochoa \& Rodríguez (2005), a Salmonella pode acarretar desde uma infecção gastrointestinal branda e evoluir para um quadro mais grave com infecção sistêmica, mas para isso, quatro fatores são levados em consideração, como o tipo de sorovar envolvido, o estado imunológico do hospedeiro, a quantidade de inócuo e os fatores de virulência manifestados pelo agente patológico.

Segundo Ohl \& Miller (2001), de acordo com a virulência do sorovar do agente, o quadro pode generalizar-se. Ou seja, o patógeno excede a camada da mucosa intestinal, apodera-se dos fagócitos e desperta mecanismo de virulência, se replica possibilitando sua sobrevivência no local. Os fagócitos infectados tendem a migrar para órgãos do sistema reticulo-endotelial (baço e fígado), contribui com a dissipação da bactéria, evoluindo para uma septicemia que pode levar a morte do hospedeiro.

A Salmonella possui um grande potencial de modular a expressão dos seus genes de virulência, resultando assim, na capacidade de suportar aos mecanismos de defesa do hospedeiro, como por exemplo, aumento de temperatura, alta osmolaridade, o peristaltismo, baixa tensão de oxigênio, microbiota local e pH estomacal (Bessa, 2006; Ochoa \& Rodríguez, 2005).

Para um melhor entendimento do mecanismo de patogenicidade é improtelável uma percepção da atuação dos genes de virulência e para isso, se faz necessário conhecer e compreender as etapas que compõem o processo infeccioso. Fazem parte dessas etapas a adesão, a invasão, replicação, resistência ao sistema imunológico e lesões ao hospedeiro, ou seja, o agente depende das condições do hospedeiro para se expressar (Ochoa \& Rodríguez, 2005).

De acordo com Edwards \& Puente (1998), a adesão é o principal mecanismo para a patogenicidade, sendo a técnica que a bactéria utiliza para se fixar nas células do organismo do hospedeiro através das adesinas que são estruturas presentes na superfície bacteriana. Desse modo, as adesinas interagem com receptores existentes na superfície da célula hospedeira.

Quando ocorre a comunicação da célula do hospedeiro com o patógeno ocasiona ativação de sinalizadores celulares, como as citocinas. Estas podem modificar a superfície da célula do hospedeiro, alterando tais receptores celulares, com isso, a reação do patógeno é oscilar o tipo de adesina apresentada (Ochoa \& Rodríguez, 2005).

A invasão confere na capacidade da bactéria de se aderir em células não fagocíticas. Essa técnica de invasão tem a função de proteger o microrganismo das defesas do organismo, propiciando sua replicação e resistência (Ochoa \& Rodríguez, 2005).

Segundo Monack et al. (2000), a bactéria salmonela após a invasão, penetra nas células da mucosa intestinal e, por fabricar efeitos citotóxicos, ocasiona a morte das células $\mathrm{M}$ e promove ocupação de enterócitos adjacentes. Além dos danos causados ao trato gastrintestinal, a bactéria provoca a morte da célula, apoptose, conduzido para o baço e fígado, começando uma infecção sistêmica. 
Essas etapas podem ser visualizadas na Figura 1, onde mostra o processo que ocorre nas etapas da patogênese da Salmonella.

É notório que, os fatores de virulência são indispensáveis aos microrganismos patogênicos com o objetivo de invadir, habitar, permanecer, proliferar no interior das células do hospedeiro e promover a doença. A remoção de qualquer um desses fatores pode ocasionar na diminuição da virulência (Suzuki, 1994).

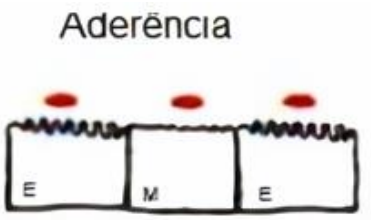

B
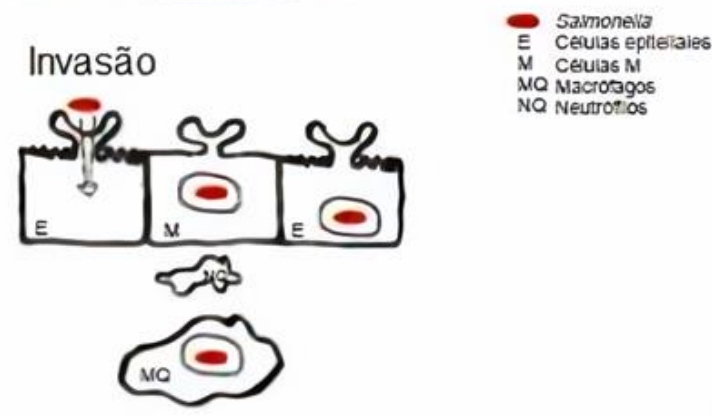

C

D

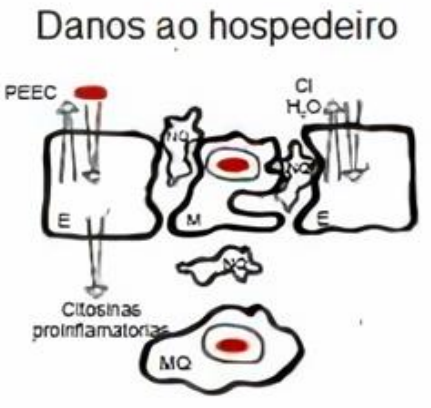

Infecção gastrintestinal
Resistência aos mecanismos de defesa
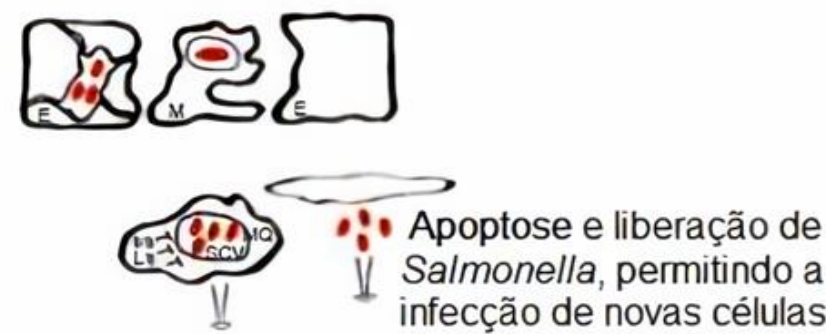

Disseminação sistêmica

Infecção sistêmica

Figura 1. Modelo representando as etapas na patogênese da Salmonella. (Letra A): Através das adesinas, os receptores são reconhecidos na superfície das células alvo (etapa de adesão). (Letra B):Ocorre a mudança na parede da célula hospedeira e o patógeno vai para o interior da célula (etapa da invasão). (Letra C): Produção de interleucina-8 (IL8) e do quimioatrator epitelial induzido por patógeno (PECC) e de citosinas inflamatórias através da célula eucariótica (etapa da infecção gastrointestinal). (Letra D): Ocorre replicação dentro dos macrófagos e induzindo a apoptose (etapa da infecção sistêmica). Fonte: Ochoa \& Rodríguez (2005).

\section{Terapêutica}

O tratamento pode ser realizado com antibioticoterapia em casos que o indivíduo apresente febre entérica e este tratamento deve perdurar por no mínimo uma semana após a cura clínica, garantindo que a bactéria salmonela seja afetada em sua localização intracelular. No tratamento das gastroenterites não é indicado o uso de antibioticoterapia, pois estende a fase de excreção do agente, padronizando o portador assintomático. Algumas outras salmonelas normalmente mostram quadro clínico restritivo com regresso espontâneo em 48 horas (Shinohara et al., 2008).

\section{Profilaxia}

Shinohara et al., (2008) diz que a prevenção e controle da Salmonella spp. é muito importante, levando em consideração que nem todos os casos são notificados ou tratados de forma certa, então devem ser adotados vários cuidados para que possam diminuir os impactos desses erros. Segundo 
Ministerio da Saúde (2019) a doença causada pela bactéria pode ser prevenida adotando medidas de controle em todas as etapas, desde a produção agrícola até o processamento, fabricação e preparação de alimentos nos estabelecimentos comerciais e nas residências.

Na produção dos animais pode ser evitado através do método de competição de exclusão competitiva, onde a colonização gastrointestinal bacteriana das aves é evitada na fase inicial das suas vidas, com uso de bactérias inócuas que irão ocupar os sítios de adesão da Salmonella spp. (Cardoso \& Carvalho, 2006).

De acordo com Raposo et al. (2019) o uso de probióticos na alimentação mostra-se uma boa alternativa no controle da zoonose nos planteis comerciais, onde o uso alternativo de probióticos se apresentou eficaz no combate a Salmonella spp.

A prevenção das doenças transmitidas por alimentos é um importante método de evitar que haja a contaminação das pessoas e os surtos na população, desse modo, é fundamental que o fornecimento e consumo de água e alimentos atendam aos padrões de qualidade estabelecidos perla legislação vigente, assim como condições adequadas de saneamento (Ministerio da Saúde, 2019).

Para prevenir a ocorrência da Salmonelose é importante adotar algumas condutas como: manter a higiene e lavagem das mãos antes, durante e após o preparo dos alimentos ou após manusear objetos sujos; lavar e desinfectar frutas, verduras e legumes antes de consumi-los; controlar a temperatura em que os alimentos são armazenado; evitar o consumo de alimentos crus ou mal cozidos e a ingestão de alimentos que contenham ovos crus; evitar a ingestão de alimentos que não sejam inspecionados (Ministério da Saúde, 2019).

\section{Salmonella spp.: importância na saúde pública}

A ocorrência das Doenças Transmitidas por Alimentos (DTAs) vem crescendo significativamente em vários países do mundo, sendo importante causadora da morbidade e mortalidade da população. A Salmonella spp. é uma das bactérias mais relevantes nos surtos, o que constitui um problema econômico e de saúde pública (Machado, 2013; Ministério da Saúde, 2010).

Há várias causas que contribuem para a Salmonelose ser um agravo à saúde pública como por exemplo, o crescente aumento das populações, a existência de grupos populacionais vulneráveis ou mais expostos, a urbanização desordenada também a necessidade de produzir alimentos em larga escala. Além disso, as condições de saneamento ineficientes, a qualidade imprópria da água para consumo humano, as práticas inadequadas de higiene pessoal somadas à falha no controle dos órgãos públicos e privados na garantia da qualidade dos alimentos ofertados à população predispõem a ocorrência dessa doença (Ministério da Saúde, 2010).

Conhecer o agente, suas características de virulência, a variabilidade genética das cepas circulantes no país, assim como o perfil de disseminação da Salmonella são fatores que podem auxiliar na implementação de programas de monitoramento e controle da doença (Mendonça, 2016). Sendo assim, o médico veterinário tem um papel importante tanto no desenvolvimento de pesquisas, quanto na elaboração de estratégias que possibilitem a prevenção e o controle das doenças veiculadas pelos alimentos (Oliveira et al., 2013). Para isso, é fundamental que os casos de Salmonelose sejam comunicados aos órgãos de saúde para que sejam investigadas as causas e a identificação do agente causador da doença (ANVISA, 2018).

Atualmente no Brasil, somente de 5 a $10 \%$ dos casos das doenças transmitidas por alimentos (DTAs) são conhecidos e registrados pelas autoridades sanitárias em função da subnotificação, ausência ou falhas na investigação dos surtos, e ainda, a não conclusão da investigação dos surtos (Ranthum, 2002). Muitas vezes isso ocorre devido à pessoa infectada ser portadora assintomática (Shinohara et al., 2008), ou os sintomas serem brandos, o que leva o indivíduo acometido a não buscar ajuda médica na maioria das vezes. Normalmente, os surtos notificados, se restringem àqueles que acometem um grande número de pessoas ou quando os sintomas têm um período de duração maior (Ministerio da Saúde, 2019; \& Comarella, 2018). Além disso, devido à semelhança dos sintomas das doenças transmitidas por alimentos, o diagnóstico é dificultado ou feito de forma errônea, o que prejudica o tratamento, o controle e ainda favorece a disseminação destes microrganismos para o ambiente (Machado, 2013). 
Outra problemática que envolve a Salmonelose, é o uso exagerado de fármacos antimicrobianos, tanto na medicina humana quanto na medicina veterinária que vem se tornando uma preocupação para os pesquisadores e para as agências de saúde no mundo todo. As bactérias patogênicas, inclusive a Salmonella spp. demonstram utilizar diferentes mecanismos que as fazem mais resistentes (Moreira et al., 2013). Para tanto é fundamental que o uso de antibióticos seja feito somente quando necessário (Ministerio da Saúde, 2019; WHO, 2018).

No Brasil, a vigilância epidemiológica das DTAs (VE-DTA) faz a monitoração dos surtos de doenças transmitidas por alimentos. De acordo com os dados do Sistema de Informação de Agravos de Notificação (Sinan, 2019), são notificados, em torno de 700 surtos, com o envolvimento de 13 mil doentes e 10 óbitos, por ano, no país (Ministerio da Saúde, 2019). De acordo com o SINAN, a região brasileira mais acometida pelas doenças transmitidas por alimentos é a Sudeste, seguida de Sul, Nordeste, Centro-Oeste e Norte, com predomínio do local de contaminação nas residências, assim como foi demonstrado no trabalho de Luca \& Koerich (2009), tendo a Salmonella como principal agente envolvido. Faz-se necessária, portanto, a adoção de programas permanentes de controle e erradicação da doença (Shinohara et al., 2008) e de programas de educação à população com treinamento de Boas Práticas de manipulação de alimentos, tanto para os trabalhadores de estabelecimentos comerciais, quanto para manipuladores domésticos (Kottwitz et al., 2010) visando desse modo o consumo de alimentos seguros do ponto de vista microbiológico.

\section{Considerações finais}

A Salmonella spp. é uma das principais bactérias presente em doenças transmitidas por alimentos, com grande importância na saúde pública mundial. Sendo assim, é fundamental conhecer essa bactéria, suas formas de transmissão, os sintomas apresentados pelos indivíduos e a patogenicidade, para que se necessário a terapêutica seja adequada. Além disso, é primordial que haja a notificação dos casos para que assim ocorra um melhor controle, e que sejam adotadas medidas de prevenção e educacionais para a população em geral, diminuindo e controlando os casos e surtos de agravos na população.

\section{Referências bibliográficas}

ANVISA. (2018). Guia de Alimentos e Vigilância Sanitária. In Agência Nacional de Vigilância Sanitátia. https://www.saude.gov.br/images/pdf/2018/janeiro/17/Guia-de-Alimentos-e-VigilanciaSanitaria.pdf

Bessa, M. C. (2006). Caracterização fenotípica e genotípica de amostras de Salmonella entérica sorovar Typhimurium isoladas de suínos no Rio Grande do Sul. Tese Doutorado em Ciências VeterináriasFaculdade de Veterinária, Universidade Federal do Rio Grande do Sul, Porto Alegre, 2006.

Brooks, G. F., Carroll, K. C., Butel, J. S., \& Morse, S. A. (2009). Microbiologia Médica. 24 ed. Rio de Janeiro: McGraw Hill, 820p.

Brooks, Geo F, Carroll, K. C., Butel, J. S., Morse, S. A., \& Mietzner, T. A. (2014). Microbiologia Médica de Jawetz, Melnick \& Adelberg - 26.ed. AMGH Editora.

Cardoso, T. G., \& Carvalho, V. M. (2006). Toxinfecção alimentar por Salmonella spp. Rev Inst Ciênc Saúde, 24(2), 95-101.

Conceição, R. C. S., Hentges, A., Moreira, Â. N., Vasconcellos, F. A., Ângelo, I. M. R., Carvalhal, J. B., Aleixo, J. A. G., \& Timm, C. D. (2007). Isolamento de Salmonella de produtos de frango e perfil de suscetibilidade dos isolados a antimicrobianos. Revista Do Instituto Adolfo Lutz (Impresso), 66(1), $31-34$.

Connor, B. A., \& Schwartz, E. (2005). Typhoid and paratyphoid fever in travellers. The Lancet Infectious Diseases, 5(10), 623-628. https://doi.org/10.1016/S1473-3099(05)70239-5

Edwards, R. A., \& Puente, J. L. (1998). Fimbrial expression in enteric bacteria: a critical step in intestinal pathogenesis. Trends in Microbiology, 6(7), 282-287. https://doi.org/10.1016/S0966$\underline{842 X(98) 01288-8}$

Fica, A., Alexandre S., M., Prat M., S., Fernández R., A., Fernández O., J., \& Heitmann G., I. (2001). Cambios epidemiológicos de las salmonelosis en Chile: Desde Salmonella typhi a Salmonella enteritidis. Revista Chilena de Infectología, 18(2). https://doi.org/10.4067/S0716- 


\section{2}

Franco, B., \& Landgraf, M. (2005). Microrganismos patogênicos de importância em alimentos. In Atheneu (1 ed). Microbiologia dos alimentos. (pp. 56-58). ed. Atheneu São Paulo.

Galdino, V. M. C. A., Melo, R. T., Oliveira, R. P., Mendonça, E. P., Nalevaiko, P. C., \& Rossi, D. A. (2013). Virulência de Salmonella spp. de origem avícola e resistência a antimicrobianos. Bioscience Journal, 29(4).

Kottwitz, L. B. M., Oliveira, T. C. R. M., Alcocer, I., Farah, S. M. S. S., Abrahão, W. S. M., \& Rodrigues, D. P. (2010). Avaliação epidemiológica de surtos de salmonelose ocorridos no período de 1999 a 2008 no Estado do Paraná, Brasil. Acta Scientiarum. Health Sciences, 32(1), 9-15.

Lima, A. W. O., \& Sousa, C. P. (2002). Infecções e intoxicações alimentares. In: Nova idéia (1 ed). Aspectos da ciência e tecnologia de alimentos. João Pessoa, PB, Brasil, p. 175-199.

Luca, A. N. B., \& Koerich, G. M. D. (2009). Perfil Epidemiológico dos Surtos de DTA Causados por Salmonella sp. em Santa Catarina, Brasil, Notificados no SINAN NET de 2006 a 2008. Monografia (Especialização)-Curso de Especialização Em Microbiologia, Departamento de Microbiologia, Pontifícia Universidade Católica Do Paraná, Curitiba, $20 \mathrm{f.}$

Machado, A. S. R. (2013). Caracterização fenotípica e genotípica de salmonelas isoladas de área rural e urbana de Manaus, Amazonas. Dissertação (Mestrado em Saúde, Sociedade e Endemias na Amazônia) - Universidade Federal do Amazonas, Manaus, 2013.

Malheiros, P. S., Paula, C. M. D., \& Tondo, E. C. (2007). Cinética de crescimento de Salmonella Enteritidis envolvida em surtos alimentares no RS: uma comparação com linhagens de outros sorovares. Ciência e Tecnologia de Alimentos, 27(4), 751-755. https://doi.org/10.1590/S0101$\underline{20612007000400013}$

Mendonça, E. P. (2016). Características de virulência, resistência e diversidade genética de sorovares de Salmonella com impacto na saúde pública, isolados de frangos de corte no Brasil. Tese (Doutorado em Ciências Veterinárias) - Universidade Federal de Uberlândia, Uberlândia, 2016.

Ministerio da Saúde. (2019). Surtos de Doenças Transmitidas por Alimentos no Brasil. In Informe 2018. Secretaria de Vigilância em Saúde (p. 16). http://portalarquivos2.saude.gov.br/images/pdf/2019/fevereiro/15/Apresenta--o-Surtos-DTA--Fevereiro-2019.pdf

Ministério da Saúde. (2010). Manual integrado de vigilância, prevenção e controle de doenças transmitidas por alimentos. Brasília: Editora do Ministério da Saúde, 2010. http://bvsms.saude.gov.br/bvs/publicacoes/manual_integrado_vigilancia_doencas_alimentos.pdf

Ministério da Saúde. (2011). Manual Técnico de Diagnóstico Laboratorial da Salmonella spp. (BrasíliaDF. 1 ed. Brasil). http://www.saude.gov.br/images/pdf/2014/dezembro/15/manual-diagnosticosalmonella-spp-web.pdf

Ministério da Saúde. (2019). Salmonella (Salmonelose): o que é, causas, tratamento e prevenção. https://saude.gov.br/saude-de-a-z/Salmonella\#: :text=O que é Salmonella (Salmonelose,enterica e S.

Monack, D. M., Hersh, D., Ghori, N., Bouley, D., Zychlinsky, A., \& Falkow, S. (2000). Salmonella Exploits Caspase-1 to Colonize Peyer's Patches in a Murine Typhoid Model. The Journal of Experimental Medicine, 192(2), 249-258. https://doi.org/10.1084/jem.192.2.249

Moreira, N. M.; Sola, M. C.; Feistel, J.C.; Oliveira, J.J.; Freitas, F.A. Os mecanismos de resistência bacteriana da Salmonella sp. frente à utilização de antibióticos. Enciclopédia Biosfera, V.9, n.16, p.11311153, 2013. Disponível em: "http://www.conhecer.org.br/enciclop/2013a/agrarias/os\%20mecanismos\%20de.pdf". Acesso em: 30 de maio de 2020.

Nadvorny, A., Figueiredo, D. M. S., \& Schmidt, V. (2018). Ocorrência de Salmonella sp. em surtos de doenças transmitidas por alimentos no Rio Grande do Sul em 2000. Acta Scientiae Veterinariae, 32(1), 47. https://doi.org/10.22456/1679-9216.16802

Neves, M. C. de M. (2016). Levantamento de dados oriundos do DATASUS relativos à ocorrências/surtos de intoxicação alimentar no Brasil de 2007-2014. Trabalho de Conclusão de Curso em Farmácia. Universidade Federal da Paraíba, João Pessoa.

Ochoa, I. M. F., \& Rodríguez, A. V. (2005). Mecanismos moleculares de patogenicidad de Salmonella 
sp. Revista Latinoamericana de Microbiología, 47(1-2), 25-42.

Ohl, M. E., \& Miller, S. I. (2001). Salmonella: A Model for Bacterial Pathogenesis. Annual Review of Medicine, 52(1), 259-274. https://doi.org/10.1146/annurev.med.52.1.259

Oliveira, A., Sola, M., Costa, J., Menezes, N., \& Oliveira, J. (2013). Salmonella enterica: genes de virulência e ilhas de patogenicidade. Enciclopédia Biosfera, 9(16), 1947-1972.

Ranthum, M. A. (2002). Subnotificação e alta incidência de doenças veiculadas por alimentos e seus fatores de risco: causas e consequencias no município de Ponta Grossa-Paraná. Dissertação (Mestrado em Saúde Pública)-Escola Nacional de Saúde Pública Sergio Arouca, Fundação Oswaldo Cruz, Rio de Janeiro, 2002.

Raposo, R. S., Defensor, R. H., \& Grahl, T. R. (2019). Uso de probióticos na avicultura para o controle da Salmonella spp.: revisão de literatura e perspectivas de utilização. Pubvet, 14(4), 1-8. https://doi.org/10.31533/pubvet.v13n4a305.1-8

Rodrigues, C. F. (2016). Pesquisa de coliformes e Salmonella spp. em ovos comercializados em feira livre, no município de Espigão do Oeste - Rondônia. Dissertação (Mestrado) - Programa de PósGraduação em Produção Animal- Universidade Brasil, São Paulo.

Shinohara, N. K. S., Barros, V. B., Jimenez, S. M. C., Machado, E. C. L., Dutra, R. A. F., \& Lima Filho, J. L. (2008). Salmonella spp., importante agente patogênico veiculado em alimentos. Ciência \& Saúde Coletiva, 13, 1675-1683.

Silva, R. A. (2012). Ciência do alimento: contaminação, manipulação e conservação dos alimentos. (p. 37). Trabalho de Conclusão de Curso (Especialização) - Universidade Tecnológica Federal do Paraná, Medianeira, 2012.

Simôes, M., Rocha, M. M. M., Pisani, B., Prandi, M. Â. G., \& Lemes-Marques, E. G. (2010). Salmonella Enteritidis: importância do inquérito epidemiológico, análise de alimentos e coprocultura na elucidação de 167 surtos alimentares. Revista Do Instituto Adolfo Lutz (Impresso), 69(4), 497-502.

Sirtoli, D. B., \& Comarella, L. (2018). O papel da vigilância sanitária na prevenção das doenças transmitidas por alimentos (DTA). Revista Saúde e Desenvolvimento, 12(10), 197-209.

Suzuki, S. (1994). Pathogenicity of Salmonella enteritidis in poultry. International Journal of Food Microbiology, 21(1-2), 89-105. https://doi.org/10.1016/0168-1605(94)90203-8

WHO. (2018). World Health Organization. 2018. Salmonella (non-typhoidal). https://www.Who.Int/News-Room/Fact-Sheets/Detail/Salmonella-(Non-Typhoidal). Acesso Em: 10 de Junho de 2020.

Recebido: 14 de julho, 2020.

Aprovado: 11 de agosto, 2020.

Disponível online: 7 de outubro, 2020.
Licenciamento: Este artigoé publicado na modalidade Acesso Aberto sob a licença Creative Commons Atribuição 4.0 (CC-BY 4.0), a qual permite uso irrestrito, distribuição, reprodução em qualquer meio, desde que o autor e a fonte sejam devidamente creditados. 